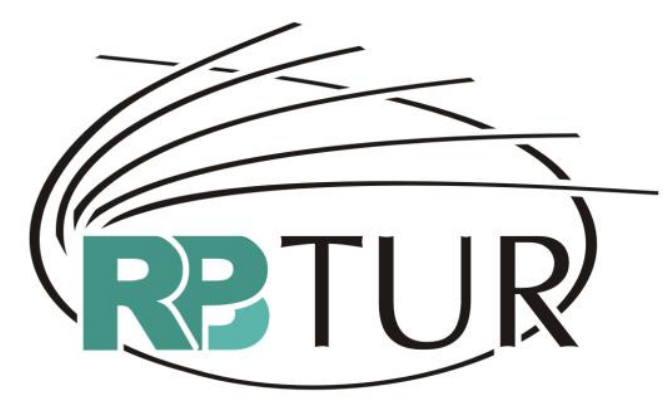

REVISTA BRASILEIRA DE PESQUISA EM TURISMO

\title{
TRABALHO, TURISMO RURAL E DESENVOLVIMENTO LOCAL NA ZONA DA MATA DE PERNAMBUCO
}

\author{
LABOUR, RURAL TOURISM AND LOCAL DEVELOPMENT IN \\ THE ZONA DA MATA OF PERNAMBUCO (BRAZIL)
}

TRABAJO, TURISMO RURAL Y DESARROLLO LOCAL EN LA
"ZONA DA MATA" (ESTADO DE PERNAMBUCO, BRASIL)

João Paulo Silva ${ }^{1}$

Maria Salett Tauk Santos ${ }^{2}$

\begin{abstract}
Resumo: Este texto tem como objetivo principal analisar a situação dos trabalhadores rurais do Engenho Itamatamirim, em Vitória de Santo Antão, Pernambuco. Esses trabalhadores, que são ex-canavieiros vêm sendo submetidos a uma jornada de trabalho que combina a atividade agrícola com o turismo rural. Por isso, busca identificar as mudanças produzidas por essa experiência nos campos do trabalho e da vida desses híbridos de agricultores e trabalhadores de turismo rural. Como procedimentos metodológicos foram utilizadas técnicas combinadas de coleta de dados, como: entrevista semi-estruturada e uso da história oral. Os resultados dessa investigação demonstraram as transformações processadas nos campos do trabalho e da vida que os ex-canavieiros do Engenho Itamatamirim tiveram nas formas de participação política, no uso do tempo livre, no lazer, no acesso às novas tecnologias da comunicação e da informação e nas aspirações para o futuro.
\end{abstract}

Palavras-chave: Turismo Rural. Trabalho. Desenvolvimento Local. Pernambuco. Brasil.

Abstract: This paper aims at analyzing the situation of rural workers of the Itamatamirim Farm in Vitoria de Santo Antao, Pernambuco. These workers, who are former sugar cane have been submitted to a workshop that combines farming with rural tourism. Therefore, traces the changes produced by this experience in the fields

1 Turismólogo, Mestre em Extensão Rural e Desenvolvimento Local pela UFRPE. Técnico da ICUBACOOP/UFRPE e Professor da Faculdade Joaquim Nabuco - Recife/PE. Email: turismo.joao@gmail.com

2 Jornalista e Doutora em Ciências da Comunicação pela ECA/USP. Coordenadora do Programa de Pós-Graduação em Extensão Rural e Desenvolvimento Local pela Universidade Federal Rural de Pernambuco - UFRPE. Email: mstauk@terra.com.br 
of work and life of these hybrids of farmers and workers in rural tourism. The methodological procedures were used combined techniques of data collection, such as semi-structured interview and oral history. The results of this investigation showed that the changes processed in the fields of work and life of the former sugar cane Itamatamirim Farm had in the forms of political participation, the use of free time, leisure, access to new technologies of communication and information and aspirations for the future.

Keywords: Rural Tourism. Work. Local Development. Pernambuco. Brazil.

Resumen: El objetivo principal de este artículo es analizar la situación de los trabajadores rurales del Ingenio Itamatamirim, en la localidad de Vitória de Santo Antão, estado de Pernambuco, Brasil. Estos trabajadores, antes cañeros, combinan ahora en su jornada de trabajo la actividad agrícola con el turismo rural. Así, se busca identificar los cambios producidos por dicha experiencia en el ámbito de trabajo y en la propia de estos trabajadores híbridos de la agricultura y el turismo. Se utilizaron como procedimientos metodológicos para la obtención de datos entrevistas semiestructuradas e historia oral. Los resultados de la investigación demuestran que las transformaciones se dieron en las formas de participación política, en el uso del tiempo libre, en la recreación, en el acceso a las nuevas tecnologías de comunicación e información y en las aspiraciones para el futuro.

Palabras clave: Turismo Rural. Trabajo. Desarrollo Local. Pernambuco. Brasil.

\section{Introdução}

O meio rural brasileiro vivencia nos últimos anos um intenso processo de transformação. Transformação nos modos de vida, nos costumes, no trabalho e nas atividades econômicas produtivas, que antes se caracterizavam apenas como agrícolas. Hoje, novas atividades produtivas e, com elas, novos atores sociais surgem no meio rural para reforçar o debate em torno das novas ruralidades (WANDERLEY, 2000). Como assinala Veiga (2002), o meio rural pode vir a se configurar como um "valor indispensável" ao futuro da sociedade, ao mesmo tempo em que os atores rurais podem passar a assumir novas funções sociais, precisamente como mediadores entre a sociedade global e os espaços rurais.

Aliado a esse processo de transformação, emerge a necessidade de incorporar essas novas atividades produtivas como aliadas na construção do desenvolvimento local em contextos rurais. O desenvolvimento local, segundo Buarque (2002) refere-se ao aproveitamento das potencialidades endógenas 
de uma localidade em prol da melhoria das condições de vida de sua população.

$\mathrm{Na}$ gestão do desenvolvimento local, além do surgimento de novas alternativas econômicas, podem ocorrer mudanças nas condições de trabalho no meio rural que, na maioria das vezes, são desiguais. Com essas transformações no meio rural, sua população, acostumada historicamente a um ritmo de vida tradicional, pode vir a se submeter a condições de trabalho mais penosas. Isso ocorre em função da busca incessante para garantir a sobrevivência de sua família, já que a manutenção da pequena produção rural já não garante mais o seu sustento.

Por essa razão é que a extensão rural possui um papel fundamental na gestão do desenvolvimento local, atenta às novas formas de trabalho e de exploração do trabalhador rural. Segundo Tauk Santos (2000), os processos de extensão rural, na contemporaneidade, devem acontecer à luz da comunicação para o desenvolvimento local, e este desenvolvimento deve se voltar à construção de mudanças envolvendo as culturas populares. Dessa forma a autora acredita que a comunicação para o desenvolvimento local no meio rural amplia a sua ação para além das atividades estritamente agrícolas, incorporando novas atividades produtivas não-agrícolas, na perspectiva de promover mudanças (TAUK SANTOS, 2000).

Entre essas novas atividades, o turismo rural tem se destacado por possibilitar o intercâmbio entre o homem da cidade e o meio rural. Por estimular atividades geradoras de benefícios econômicos e culturais, Del Grossi e Graziano da Silva (2002) acreditam que o turismo rural está mudando a mentalidade de muitos fazendeiros e sitiantes do interior do Brasil. Juntamente com a produção agropecuária, a exploração turística rural vem sendo encarada como mais um produto capaz de gerar empregos e divisas locais.

O Estado de Pernambuco é um destino que vem se mostrando fértil para o desenvolvimento do turismo rural. O poder público estadual junto com a iniciativa privada tem buscado incentivar cada vez mais antigos engenhos de cana-de-açúcar a investir no turismo como uma alternativa economicamente 
viável. Com isso, os agricultores da região, em sua maioria canavieiros, vêm sendo envolvidos nessa proposta como forma de aumentar sua renda familiar e garantir sua sobrevivência, já que a cana-de-açúcar não representa mais uma fonte de renda segura em função de seu caráter sazonal.

Todavia, com o desenvolvimento do turismo rural pernambucano centralizado nos grandes empresários do setor canavieiro, os "senhores de engenho", as populações de contextos populares rurais têm sido levadas a uma mudança significativa nas suas vidas. O trabalho com o turismo rural, em alguns casos, tem submetido essas pessoas a condições precárias de trabalho em função da necessidade que têm de garantir melhores condições de vida para suas famílias (TAUK SANTOS et al, 2001).

O trabalhador rural, nesse caso, pode ser impelido a desenvolver várias atividades produtivas, gerando tensões em diversos domínios de sua vida. Essa condição pode ser observada no turismo rural, por exemplo, quando agricultores que tradicionalmente trabalhavam na lavoura canavieira passam a ser exigidos para trabalhar simultaneamente em atividades do setor de serviços (TAUK SANTOS et al, 2001).

Fenômeno semelhante vem ocorrendo no Engenho Itamatamirim, localizado no Município de Vitória de Santo Antão, Zona da Mata de Pernambuco: esse antigo engenho deixou de explorar a cana-de-açúcar em meados de 1980 e passou a investir na pecuária, na piscicultura e, posteriormente, apostou no turismo rural como uma possibilidade de crescimento econômico para a propriedade.

Vivendo atualmente dentro do Engenho Itamatamirim é possível encontrar algumas famílias de ex-canavieiros que passaram a trabalhar com o turismo rural sem abandonar a atividade agrícola. Essa mudança tem levado essas pessoas a desenvolverem novas práticas produtivas, agora ligadas ao setor de serviços.

Nesse momento, surge a discussão em torno das reais possibilidades do turismo rural como um dos agentes propulsores do desenvolvimento local em tempos de novas ruralidades, uma vez que, no Engenho Itamatamirim, o que 
se observa é que trabalhadores rurais tradicionais foram levados a desenvolver atividades tipicamente urbanas, para as quais não foram devidamente treinados.

Portanto, o presente texto tem como objetivo principal analisar a situação dos trabalhadores rurais do Engenho Itamatamirim, que vêm sendo submetidos a uma jornada de trabalho que combina a atividade agrícola com a nova proposta de turismo rural na perspectiva do desenvolvimento local. Especificamente, busca identificar as mudanças produzidas por essa experiência nos campos do trabalho e da vida desses híbridos de agricultores e trabalhadores de turismo rural.

\section{A Pesquisa}

Optamos pela pesquisa qualitativa para analisar a situação dos excanavieiros do Engenho Itamatamirim num campo de trabalho que combina duas atividades distintas. Conforme Godoy (1995), a perspectiva qualitativa auxilia a compreensão do fenômeno no momento em que o analisa de maneira integrada. A investigação predominantemente qualitativa se volta para explicar o processo social em profundidade, captando a maneira de ser do objeto pesquisado e tudo que o diferencia dos demais (GODOY, 1995).

A pesquisa configura-se também como um estudo de caso. Segundo Yin (2005), estudos de caso são as estratégias preferidas quando as questões "como" ou "por que" estão presentes e quando o pesquisador tem baixo controle de uma situação que, por sua natureza, esteja inserida em contextos sociais.

Foram utilizadas técnicas combinadas de coleta de dados, como pesquisa bibliográfica, observação direta e uso da história oral. Recorremos à técnica da história oral, buscando preencher as lacunas existentes nos documentos escritos, a partir dos depoimentos da população em estudo. Segundo Haguette (1987, p.83), a história oral é uma técnica de coleta de dados "baseada no depoimento oral, gravado, obtido através da interação entre o especialista e o 
entrevistado, ator social ou testemunha de acontecimentos relevantes para a compreensão da sociedade". O uso da história oral, nesse contexto, está associado à necessidade de uma reconstituição histórica sobre um determinado tema ou população.

Nessa perspectiva, foi elaborado um roteiro de entrevista semiestruturado composto de três blocos voltados à identificação dos entrevistados, à caracterização do trabalho na pecuária e à caracterização do trabalho no turismo rural. Em todos esses momentos foram consideradas também as mudanças na atividade laboral e em outros domínios da vida, como na participação política, no uso do tempo livre e do lazer, no uso dos meios de comunicação e nas aspirações para o futuro.

A escolha dos entrevistados foi intencional, obedecendo-se aos seguintes critérios: pessoas oriundas da agricultura canavieira e que, hoje, desenvolvem no Engenho Itamatamirim outras atividades agrícolas voltadas à pecuária e à piscicultura, ao mesmo tempo em que também atuam como trabalhadores do turismo rural nos equipamentos de lazer existentes no referido Engenho. Identificamos, com isso, cinco trabalhadores rurais que possuem essas características e que constituíram a população analisada neste estudo.

\section{O Trabalho no Novo Rural Brasileiro: da Modernização Dolorosa ao Turismo Rural}

O mundo do trabalho como recorte epistemológico dessa pesquisa se justifica pelo fato de, conceitualmente, a categoria trabalho ter importância fundamental para a compreensão das transformações que vêm ocorrendo na sociedade contemporânea (ANTUNES, 1995), sobretudo nos contextos populares, pelas dificuldades que essas pessoas têm de acesso à formação profissional, treinamentos, capacitações etc..

Para Antunes (1995), as mudanças no mundo do trabalho possuem relação direta com a introdução das novas tecnologias e com o crescimento da economia capitalista, gerando novas formas de trabalho e de relações de 
trabalho. O autor ainda afirma que o trabalho é responsável por criar formas de intercâmbio entre o setor social e a natureza, criando também novos valores de uso a partir do consumo simbólico de bens e serviços, característica do mundo capitalista (ANTUNES, 1995).

Nos últimos 20 anos do século $X X$, a sociedade mundial tem vivenciado uma reestruturação produtiva do capital, que trouxe consigo novas formas de produção e de trabalho. Segundo Carleial (1997), esse movimento resultou em alterações profundas no processo de acumulação e (re)produção de capitais e em uma verdadeira metamorfose nas relações de trabalho com conseqüências danosas para os movimentos sindical e operário e para a classe trabalhadora de uma forma geral.

No meio rural brasileiro, as transformações no mundo do trabalho vem gerando impactos dolorosos aos pequenos e médios produtores. Analisando a história, essas mudanças começaram a ficar mais evidentes em meados de 1970, quando se observou a elevação da produção agrícola, dos níveis de exportação e dos preços reais dos produtos. Apesar desse crescimento econômico da produção, Graziano da Silva (1982) ressalta que a renda da maioria dos agricultores manteve-se num nível muito baixo e a geração de postos de trabalho também esteve aquém do crescimento produtivo que se apontava naquele período.

A solução que as esferas do poder público encontraram para esse cenário de crise foi o da modernização da agricultura nacional. Contudo, a "modernização dolorosa", como chamou Graziano da Silva (1982), acentuou a sazonalidade da ocupação de uma mão-de-obra cada vez mais não-qualificada, que era exigida por ocasião das colheitas. Para o mesmo autor, "a modernização aumenta as exigências e diminui o período de ocupação da mãode-obra não qualificada numa dada propriedade agrícola" (p. 30). A solução encontrada pelo empresário rural, segundo o autor, foi a de substituir o trabalhador permanente pelo volante, o que aumentou a sazonalidade do emprego no meio rural e constituiu, a partir daí, o surgimento de novas formas de trabalho. 
Em meio à modernização agrícola, a Região Nordeste, com a criação da Superintendência do Desenvolvimento do Nordeste (SUDENE), em dezembro de 1959, viu o Governo Federal se propor a trazer fortes mudanças à organização do setor primário (ANDRADE, 1988). No Estado de Pernambuco, por exemplo, esse processo atingiu diretamente 0 setor canavieiro, fortalecendo um sistema contraditório que impulsionava o êxodo rural e desvalorizava cada vez mais o pequeno produtor. Em meados dos anos 1990, a agroindústria açucareira em Pernambuco sofreu uma forte crise, o que provocou a falência de muitos usineiros.

A modernização agrícola significou para o espaço rural pernambucano uma transformação muito grande nos modos de vida e nas relações de trabalho (ARAÚJO, 2002). Atualmente, Pernambuco tem vivido um momento de muitas transformações em favor do desenvolvimento regional, com a introdução de novas indústrias e com o fortalecimento do turismo.

Por isso, vivenciamos atualmente uma tendência que observa a atividade turística como um importante vetor de desenvolvimento local no meio rural. Quando bem planejada, essa atividade tende a garantir a sustentabilidade dos recursos naturais e do patrimônio histórico-cultural de diversas comunidades rurais. Esse processo pode estimular a intervenção positiva de órgãos públicos, bem como parcerias de instituições privadas, a fim de contribuir cada vez mais para construção do desenvolvimento local de forma sustentável.

\section{Turismo Rural e Desenvolvimento Local}

Nos últimos anos a prática do turismo rural tem se expandido no mundo por ser considerada uma atividade que pode contribuir para o desenvolvimento local do meio rural. A expressão turismo rural tem sido utilizada para designar qualquer atividade turística no espaço rural onde predominem atividades ligadas ao setor primário da cadeia produtiva, à agricultura, à criação ou ao extrativismo. O Ministério do Turismo (MTUR) define o turismo rural como 
O conjunto de atividades turísticas desenvolvidas no meio rural, comprometido com a cultura no meio rural e com a produção agropecuária, agregando valor a produtos e serviços, resgatando e promovendo o patrimônio cultural e natural da comunidade (MTUR, 2009, p.7).

Analisando a definição do MTUR, é possível afirmar que o turismo rural, ao ser promovido como um vetor de desenvolvimento local, contribui para a economia, para a preservação do patrimônio cultural e natural e para a melhoria da vida das famílias que estão envolvidas diretamente com a atividade.

Contudo, é importante, como salienta Fontana e Dencker (2006), destacar que ainda existe uma distância do discurso teórico e o que acontece de fato, na prática. O turismo rural tem sido muitas vezes colocado como a melhor entre todas alternativas de diversificação de renda para o produtor rural. Na verdade, o que em alguns casos ocorre é a implantação da atividade turística rural "de forma improvisada e sem o auxílio de um profissional de turismo qualificado, acarretando sérios problemas tanto na questão ambiental, como socioeconômica da propriedade e comunidade local" (FONTANA \& DENCKER, 2006, p.7).

Para encarar essa nova condição de trabalho, os trabalhadores rurais passam a depender de treinamentos de curta duração realizados pelas instituições públicas ligadas ao desenvolvimento do turismo rural que geralmente repassam os conteúdos em um ritmo diferente daquele ao qual esses trabalhadores estão acostumados (TAUK SANTOS et al, 2001).

Tauk Santos et al (2001) demonstrou no estudo realizado em Nazaré da Mata/PE que o trabalho com o turismo rural passou a afetar diretamente o cotidiano dos ex-canavieiros. Isso porque a introdução da atividade turística não altera apenas os valores sociais dessa população, mas também pode influenciar no processo de organização e divisão social do trabalho no interior do grupo doméstico, redefinindo papéis exercidos pelos membros da família.

A nova forma de organização do trabalho a que estão submetidos esses trabalhadores rurais pode influenciar também na maneira de encarar a vida, de 
cuidar dos filhos, de usar os meios de comunicação, de usufruir do tempo livre e de participar de organizações políticas ou recreativas, bem como redefinir papes dentro da ambiente familiar (ALMEIDA \& SILVA, 2001).

Outro impacto significativo sobre a população rural, resultado do desenvolvimento turístico, está relacionado às formas de moradia. No caso dos ex-canavieiros, por exemplo, a população passa a residir em casas dentro dos engenhos, não pagam aluguel e podem plantar um roçado para consumo da família e para vender na feira (TAUK SANTOS et al, 2001).

A partir das mudanças relativas à atividade produtiva, as relações dos trabalhadores com o tempo livre e as formas de desfrutá-lo também pode sofrer influências. Eles agora se vêem na obrigação de cumprir um horário fixo, mesmo que haja pouco trabalho a ser feito e que as tarefas sejam consideradas mais leves. Muitos trabalhadores também aproveitam para se ocupar em outras atividades que proporcionem alguma renda extra, executando funções como pedreiro, vigilante, motorista, jardineiro, garçom, etc. (GRAZIANO DA SILVA, 1997).

Além dessas mudanças, a jornada de trabalho pode vir a caracterizar uma condição de polivalência. Na expressão "polivalência" se reconhece um significado que, de modo mais ou menos empírico, é comum a todos: trabalhador polivalente é aquele capaz de realizar uma multiplicidade de tarefas (XAVIER, 1997). Não propriamente um "faz-tudo", um "pau para toda a obra", mas, segundo Xavier (1997), alguém com múltiplas obrigações, que se vê na necessidade de enfrentar os imprevistos surgidos no oferecimento da sua prestação.

Todos esses impactos relacionados ao trabalho no turismo rural diminuem a possibilidade dessa atividade agir efetivamente como um impulsionador do desenvolvimento local. Segundo Tauk Santos e Callou (2006) o desenvolvimento local surge como uma possibilidade promissora para enfrentar os problemas dos contextos populares, derivados, sobretudo, da crise nos modelos de intervenção fundamentados na difusão de inovações. 0 desenvolvimento local deve buscar saída para questões imediatas encontradas 
numa determinada localidade, como o problema da fome, educação, saúde, desemprego, migração, ou seja, problemas sociais que promovem a exclusão dos contextos populares (TAUK SANTOS, 2000).

Jesus (2003) afirma que somente há desenvolvimento local quando há também uma mudança que se traduz em benefícios para as comunidades locais. Esses benefícios não estão relacionados apenas à geração de renda, mas também a outros indicadores do desenvolvimento local, tais como a participação, a preservação ambiental, a valorização da cultura local, o acesso ao conhecimento, entre outros (FRANCO, 2000).

\section{O Turismo Rural no Engenho Itamatamirim (Pernambuco)}

Ao enveredar pelo turismo rural, o produtor passa por uma série de transformações na sua vida, que inclui não só questões relacionadas à renda, mas também ao modo de encarar a vida, a religião, o lazer e o tempo livre. Nesse sentido, além da categoria trabalho, as transformações processadas pelas novas atividades produtivas em outros domínios da vida desses sujeitos também foram consideradas, como nas formas de participação política, no uso do tempo livre, no lazer e nas aspirações para o futuro, como veremos a seguir.

\section{a) Participação política}

A participação é entendida como um esforço de desenvolvimento local, pois atua na construção de uma nova cidadania (JARA, 1998). No que tange às organizações produtivas, todos os entrevistados afirmaram que participam da Associação de Produtores Rurais de Galiléia ${ }^{3}$, localizada na zona rural de Vitória de Santo Antão. Embora os ex-canavieiros do Engenho Itamatamirim estejam

\footnotetext{
${ }^{3} \mathrm{O}$ movimento que se tornou nacionalmente conhecido como Ligas Camponesas iniciou-se no Engenho Galiléia, em Vitória de Santo Antão, nos limites da região do Agreste com a Zona da Mata de Pernambuco.
} 
envolvidos atualmente com o turismo rural, eles colocaram que essa questão não é discutida na associação que participam, tampouco existe o interesse de outros produtores em se engajar na proposta da atividade turística, como pode ser observado na fala desse trabalhador:

Acho que não tem nada a ver, porque a associação é de produtores rurais e o turismo é outra coisa. Se fosse uma associação de turismo, aí a gente poderia discutir mais (ENTREVISTADO 02).

A partir dessa constatação, foi ouvido o Presidente da Associação ${ }^{4}$ na intenção de confrontar as informações dadas pelos trabalhadores rurais do Engenho Itamatamirim. Quando questionado sobre o turismo rural, afirmou:

Aqui não é lugar pra falar de turismo, de artesanato, de coisas que não interessam. Se eles querem falar de turismo, têm que montar uma associação de turismo (PRESIDENTE DA ASSOCIAÇÃO, 2010).

Entende-se que, nesse caso, a associação a qual estão vinculados não Ihes deixa a opção de participar ou não das novas atividades produtivas nãoagrícolas, como o turismo, que passam a ser desenvolvidas dentro das grandes propriedades na perspectiva do desenvolvimento local.

b) Tempo livre e lazer

Foi observado que os trabalhadores do Engenho Itamatamirim quase não dispõe de tempo livre, com exceção da noite, quando não estão trabalhando. Quando podem desfrutar de algum tempo livre durante a semana, aproveitam para se divertir. As formas de diversão mais citadas foram: assistir televisão, escutar rádio, jogar futebol, ler jornal e revista e descansar.

Quanto à questão do lazer, foi observado que, embora o tempo livre seja escasso, alguns trabalhadores afirmaram que se divertem mais do que quando eram canavieiros, como ilustram as falas a seguir:

\footnotetext{
${ }^{4}$ José Maria de Medeiros, em entrevista ao pesquisador em janeiro de 2010.
} 
Quando eu cortava cana eu não tinha vida de jovem. Só era trabalhando. Hoje eu me divirto mais, saio mais. Dou mais valor a vida. Não quero ter a vida que meu pai teve, só de trabalho. A gente precisa de um lazer (ENTREVISTADO 03).

Eu hoje faço coisas que não fazia antes. Eu jogo bola e me divirto no carnaval. Antigamente eu não fazia muitas coisas. As coisas por aqui eram muito difíceis pra gente. Ir na cidade, mesmo, era uma festa. Quando a gente ia pra feira era o único lazer que a gente tinha (ENTREVISTADO 05).

O lazer pode contribuir, como afirma Dumazedier (1994), para o desenvolvimento da personalidade do indivíduo, que libera os limites que impõe o meio social, o ambiente cultural, a especialização técnica e, por isso, representa uma categoria fundamental ao desenvolvimento local.

c) Uso dos meios de comunicação

Hoje em dia, a prática de assistir televisão nos momentos que não estão trabalhando, sobretudo à noite, foi mencionada como a principal forma de ocupar o tempo livre nesse horário, como podemos constatar nas falas:

O negócio é assistir televisão que a gente aprende. Não aprende quem não quer. A televisão tem muita coisa pra ensinar e a gente pode usar no dia-a-dia (ENTREVISTADO 01).

Eu passei a assistir mais televisão para ficar mais informado. Hoje qualquer assunto que você falar aí eu conheço, porque assisto muito televisão e ouço rádio também (ENTREVISTADO 02).

Entre as diversas mídias, o rádio foi apontado como o único meio que esteve presente desde o período em que esses trabalhadores cortavam canade-açúcar. Naquela época, era o rádio a principal mídia utilizada para a comunicação e informação dos trabalhadores rurais daquela região e ainda hoje é apontado por esses indivíduos como um dos meios que têm a 
preferência entre os residentes do Engenho Itamatamirim, como pode ser ilustrado na fala:

O rádio ainda é melhor do que a televisão porque a gente pode levar para onde quiser. Leva para o trabalho, fica escutando. Hoje, a programação do rádio está bem melhor do que antigamente. Hoje você tem notícia, piadas, bastante coisa (ENTREVISTADO 04).

Isso demonstra a importância que os meios de comunicação têm para o trabalho que esses ex-canavieiros realizam atualmente, sobretudo no turismo rural. A mídia, nesse contexto, atua como uma espécie de manual da modernidade, da cultura de massas, e por isso serve à atividade do turismo através do uso dos meios de comunicação e da informação.

\section{d) Aspirações para o futuro}

Para todos os entrevistados, o fato de estarem trabalhando atualmente com o turismo rural melhorou em alguns aspectos a condição de vida que tinham antes. Eles se consideram mais articulados, mais integrados e mais participativos.

Contudo, o trabalho intenso que esses ex-canavieiros desenvolvem dentro do Engenho Itamatamirim pode trazer conseqüências, não só no desgaste físico e mental desses trabalhadores, mas também quanto às perspectivas de crescimento profissional dos mesmos, pois em uma condição de trabalho polivalente a que estão submetidos, acabam não se dedicando com mais profundidade a nenhuma das atividades que desenvolvem.

Há aqueles que perseguem a possibilidade de participar de mais cursos de capacitações a fim de Ihes possibilitar atuar em outras atividades do turismo rural dentro do próprio Engenho Itamatamirim, como se observa:

Se a gente tivesse mais capacitações poderia até trabalhar em outras funções. Penso no futuro e acho que o turismo pode ser uma boa saída porque tem muitos cursos e faculdade de turismo por aí (ENTREVISTADO 04). 
Ao terem contato com atividades que exigem um maior nível técnico para serem executadas, como acontece no turismo rural, alguns trabalhadores passam a se interessar pela participação em cursos de qualificação na área de turismo, o que demonstra o anseio de investir em um nível mais elevado de formação para atuar no turismo rural e galgar novas oportunidades profissionais nesta área:

Hoje eu vejo que posso crescer muito no turismo rural. Eu tenho vontade de fazer faculdade de turismo um dia, ou então um curso técnico. Porque isso aqui vai crescer muito ainda (ENTREVISTADO 03).

Quando os trabalhadores rurais entrevistados comparam o trabalho no turismo rural com o trabalho que desenvolviam na agricultura canavieira, alguns afirmam que os benefícios proporcionados pelo setor de serviços são bem mais evidentes do que se ainda estivessem atuando como canavieiros, como pôde ser ilustrado com as falas a seguir:

O trabalho no turismo rural, pelo que eu vejo, é bem melhor. Se você me perguntar se eu queria deixar de trabalhar na roça, na pecuária, eu vou dizer que não. Mas eu queria trabalhar mais com turismo, porque acho muito prazeroso (ENTREVISTADO 01).

Eu gosto de trabalhar com o turismo. Acho que levo jeito pra coisa. O turismo rural é uma atividade nova, vai crescer muito ainda e a agricultura canavieira está em decadência (ENTREVISTADO 05).

Apesar de alguns trabalhadores demonstrarem satisfação com o turismo rural, essa atividade não deve ser vista ou promovida como a solução de todas as dificuldades do meio rural, como acaba aparecendo em alguns momentos no discurso do poder público e da iniciativa privada (FROEHLICH, 2002). Diante disso, Fontana e Dencker (2006) afirmam que se torna importante o processo de planejamento e implantação atividade turística, preservando as raízes e atividades cotidianas da propriedade, sendo essas características os principais atrativos para quem busca o turismo rural. 
Dessa forma, o turismo rural é uma atividade que deve ser vista e entendida como sendo um complemento às atividades agrícolas das propriedades rurais, de tal forma que o cotidiano da vida rural, em menor ou maior intensidade, continue a existir, sem prejudicar o tempo livre, o lazer e os costumes tradicionais das famílias rurais que passam a trabalhar com turismo rural, como é o caso do Engenho Itamatamirim.

\section{Considerações Finais}

No presente trabalho, os resultados revelaram que a passagem da condição de cortador de cana-de-açúcar para a de trabalhador do turismo rural proporcionou uma transformação intensa em diversos domínios da vida dessas pessoas, sobretudo no trabalho.

O que se constatou é que os trabalhadores rurais do Engenho Itamatamirim não sentem saudades da época em que eram canavieiros, por considerar que esse tipo de atividade era desgastante e não proporcionava muitos benefícios a suas famílias. Embora a atual jornada de trabalho tenha se intensificado, eles consideram que o trabalho que desenvolvem hoje na pecuária e no turismo rural é mais gratificante e seguro do que o corte de cana-de-açúcar. No turismo rural, o maior problema diagnosticado pelos trabalhadores rurais foi a falta de capacitações e cursos de qualificação profissional para atuarem melhor na prestação de serviços. Isso demonstra que esses trabalhadores, apesar de estarem trabalhando com o turismo rural há algum tempo, ainda possuem dificuldades no desenvolvimento de suas atividades.

Quanto ao uso dos meios de comunicação, percebeu-se que a televisão é a mídia que mais utilizam no seu dia-a-dia, tanto para entretenimento como para obter informações que podem vir a ser úteis ao seu trabalho.

As aspirações para o futuro revelaram que, embora a atividade no turismo rural ainda não esteja formalizada para esses trabalhadores, os mesmos afirmaram que não pretendem abandoná-la, pois o envolvimento na 
atividade mudou consideravelmente suas vidas, seja na moradia, na renda, no acesso à informação e, principalmente na auto-estima. Contudo, o principal desejo dessa população é o de dar continuidade aos estudos, fazer cursos de qualificação profissional, entrar na universidade e acessar novas tecnologias que podem contribuir para o seu trabalho.

Nesse contexto, reside a importância da extensão rural como gestora dos processos de desenvolvimento local, abrindo espaço para o diálogo com instituições de pesquisa, escolas técnicas e universidades, no intuito de somar esforços para mudar o cenário atual de exclusão e desigualdades sociais no meio rural.

Sabe-se que o meio rural brasileiro é marcado historicamente por constituir um espaço de desigualdade. É importante ficar atento a reprodução dessas desigualdades também no turismo rural, sobretudo nas relações sociais que se estabelecem entre os proprietários/empresários de turismo e os trabalhadores rurais, como vem ocorrendo no Engenho Itamatamirim.

Todavia, entende-se que a experiência do Engenho Itamatamirim representa um processo em construção, um cenário de possibilidades e, por isso, pode ser considerada como um esforço de desenvolvimento local no momento em que mobilizou, através do turismo rural, capacidades e energias endógenas, gerou novos postos de trabalho, possibilitou aos indivíduos envolvidos o acesso à informação e estimulou a valorização da educação para o seu crescimento profissional. Entretanto, é importante prestar atenção às evidências dessa pesquisa para que a experiência de turismo rural seja aperfeiçoada a fim de profissionalizar e formalizar esse processo, fundamental ao desenvolvimento local.

\section{Referências}

ALMEIDA, J.A.; SILVA, M. F. O turismo rural transformando os papéis do grupo familiar. In: 30 CONGRESSO BRASILEIRO DE TURISMO RURAL, Piracicaba. Anais... Piracicaba: FEALQ, 2001.

ANDRADE, M. C. Terra e homem no Nordeste. São Paulo: Brasiliense, 1986. 
ARAÚJO, J. G. F. ABC do turismo rural. Viçosa: Aprenda Fácil, 2000.

ANTUNES, R. Adeus ao trabalho? Ensaio sobre as metamorfoses e a centralidade do mundo do trabalho. São Paulo: Cortez, 1995.

BUARQUE, S. Construindo o desenvolvimento sustentável. Rio de Janeiro: Geramond, 2002.

CARLEIAL, L. Flexibilidade e seus efeitos sobre a organização da produção, assalariamento e ação sindical: especificidades setoriais e regionais. Curitiba: Relatório de Pesquisa/FINEP, Versão preliminar(mimeo), 1997.

DEL GROSSI, M. E.; GRAZIANO DA SILVA, J. O novo rural: uma abordagem ilustrada. Londrina: IAPAR, 2002.

DUMAZEDIER, J. A revolução cultural do tempo livre. São Paulo: Studio Nobel/SESC, 1994.

FONTANA, R. F.; DENCKER, A.F.M. Turismo Rural: desencontros de uma realidade. In: IV SEMITUR - SEMINÁRIO DE PESQUISA EM TURISMO DO MERCOSUl. Caxias do Sul. Anais.... Caxias do Sul: Universidade Federal de Caxias do Sul, 2006.

FRANCO, A. Porque precisamos de desenvolvimento local integrado e sustentável. Brasília: Instituto de Política, 2000.

FROEHLICH, J. M. Turismo rural e agricultura familiar: explorando (criticamente) o cruzamento de abordagens e estratégias para 0 desenvolvimento local. São Paulo: INTERCOM; Recife: Bagaço, 2002.

GODOY, A. S. Introdução à pesquisa qualitativa e suas possibilidades. Revista de Administração de Empresas, São Paulo, v. 35, n.2, Mar/Abr de 1995.

GRAZIANO DA SILVA, J. O novo rural brasileiro. Belo Horizonte: Nova Economia, 1997.

. A modernização dolorosa. Rio de Janeiro: Zahar, 1982.

HAGUETTE, T. M. F. Metodologias qualitativas na sociologia. São Paulo: Vozes, 1987.

JARA, C. J. A sustentabilidade do desenvolvimento local. Brasília: IICA; Recife: SEPLAN, 1998.

JESUS, P. Desenvolvimento local. In: CATANI, A. D (Org.). A outra economia. Porto Alegre: Veraz, 2003.

MTUR. Ministério do Turismo. Diretrizes para o desenvolvimento do turismo rural no Brasil. Brasília, 2004. Disponível em: <http://www.embratur.gov.br/0-catalogo-documentos/arquivos-

internos/Diretrizes -Turismo Rural.pdf> Acesso em 06 de Junho de 2009.

VEIGA, J. E. Cidades imaginárias. Campinas: Editores Associados, 2002.

WANDERLEY, N. A emergência de uma nova ruralidade nas sociedades modernas avançadas - o "rural" como espaço singular e ator coletivo. Estudos Sociedade e Agricultura, 15, outubro 2000: 87-145.

TAUK SANTOS, M. S.; CALLOU, A. B. F. (Orgs.). Associativismo e desenvolvimento local. Recife: Bagaço, 2006.

TAUK SANTOS, M. S. et al. Políticas de comunicação e as novas ruralidades: estudo de recepção das propostas de turismo rural pelos canavieiros do Engenho Santa Fé, Pernambuco. In: XXIV CONGRESSO BRASILEIRO DA 
ISSN: $1982-6125$

COMUNICAÇÃO. Campo Grande. Anais... Campo Grande: Universidade Federal do Mato Grosso do Sul, 2001.

- Comunicação Rural - velho objeto, nova abordagem: mediação, reconversão cultural, desenvolvimento local. In: LOPES, M. I. V.; FRAUGMEIGS, D.; TAUK SANTOS, M. S. (Orgs). Comunicação e Informação: Identidades e Fronteiras. São Paulo/Recife: Intercom e Edições Bagaço, 2000. XAVIER, B. L. A mobilidade funcional e a nova redacção do art. $22^{\circ}$ da LCT. Revista de Direito e Estudos Sociais, Lisboa, no. s. 1-2-3, 1997. YIN, R. K. Estudo de caso: planejamento e métodos. Tradução Daniel Grassi. 3.ed. Porto Alegre: Bookman, 2005.

Artigo recebido em julho de 2010.

Aprovado para publicação em novembro de 2010. 